\title{
Seeing the air quality of carbon monoxide in Makassar city: The CSR program of PT Pertamina IT
}

\author{
Krisno Bimantoro ${ }^{1}$, Andi Ade Ula Saswini ${ }^{2}$, Mustof ${ }^{3}$ \\ ${ }^{1,2,3}$ PT Pertamina Integrated Terminal Makassar
}

\begin{abstract}
The high number of residents in urban areas accompanied by an increase in motor vehicle users can be a trigger for increasing concentrations of Carbon monoxide emissions. The purpose of this monitoring activity is as follows, namely to obtain air quality data / information on CO (carbon monoxide) parameters as a basis for comparing the air quality of CO parameters before and after the CSR (corporate social responsibility) Program Asri Wall which is then analyzed based on the Air Pollution Standard Pollution Index (ISPU). Air quality monitoring is carried out in three locations of Intervention CSR Program which has the potential to cause air pollution, especially carbon monoxide (CO) gas impact on public health. The results of air quality monitoring showed the average value of CO concentrations during / before the implementation of the CSR Wall Asri program was higher, compared to after the implementation of the CSR program. The Value Analysis of the Air Pollution Standard Index (ISPU) during / before the implementation of the CSR program is more dangerous to health and is categorized as Very Unhealthy, while the ISPU value after the implementation of this CSR Program has decreased in value and is in the Unhealthy category. Therefore, it can be concluded that the air quality at the CSR Program Intervention Location experienced an improvement in air quality after the implementation of the Asri CSR Program.
\end{abstract}

Keyword: air quality; carbon monoxide; co; makassar

\begin{abstract}
ABSTRAK
Tingginya jumlah penduduk di perkotaan yang disertai dengan bertambahnya pengguna kendaraan bermotor dapat menjadi pemicu meningkatnya konsentrasi emisi Karbon monoksida. Tujuan pelaksanaan kegiatan pemantauan ini adalah sebagai berikut, yaitu untuk mendapatkan data/informasi kualitas udara parameter CO (karbon monoksida) sebagai dasar untuk membandingkan kualitas udara parameter CO sebelum dan seletah program CSR Dinding Asri yang kemudian dianalisis berdasarkan Indeks Pencemaran Standar Pencemar Udara (ISPU). Pemantauan kualitas udara dilaksanakan di tiga titik lokasi Intervensi Program CSR yang berpotensi menimbulkan dampak pencemaran udara khususnya gas karbon monoksida (CO) terhadap kesehatan masyarakat. Hasil pemantauan kualitas udara menunjukkan nilai rata-rata konsentrasi CO pada saat/sebelum dilaksanakannya program CSR Dinding Asri lebih tinggi, dibandingkan setelah pelaksanaan program CSR. Nilai Analisis Indeks Standar Pencemar Udara (ISPU) pada saat/sebelum dilaksanakannya program CSR ini lebih beresiko berbahaya terhadap kesehatan dan masuk dalam kategori Sangat Tidak Sehat, sedangkan nilai ISPU setelah dilaksanakannya Program CSR ini mengalami penurunan nilai dan masuk kategori Tidak Sehat. Maka dari itu dapat disimpulkan bahwa kualitas udara di Lokasi Intervensi Program CSR, mengalami perbaikan kualitas udara setelah dilaksanakannya Program CSR Dinding Asri.
\end{abstract}

Kata kunci: kualitas udara; karbon monoksida; co; makassar

\section{PENDAHULUAN}

Jumlah kendaraan yang beroperasi diseluruh indonesia dari tahun 2012-2014 mengalami kenaikan 12\% menjadi 104,211 juta unit dan sebagian besar disumbangkan
Peningkatan jumlah kendaraan setiap tahunnya dapat mengakibatkan kemacetan di ruas jalan kota, yang pada akhirnya akan berakibat terjadinya buangan emisi ken- 
daraan bermotor. Disektor transportasi, buangan emisi kendaraan baik dari motor, mobil ataupun bus dapat berkontrisi besar terhadap terjadinya polusi udara secara lokal. (Derrible et al., 2010)Gas buangan yang paling banyak dihasilkan adalah Karbon Monoksida (CO) dengan proporsi buangan sebesar 71\% (Wardhana, 1995). Karakteristik CO yang tidak berwarna, berbau dan berasa serta daya toksik yang tinggi dapat mempengaruhi kesehatan manusia, selain itu gas CO berkontribusi besar terhadap terjadinya efek rumah kaca (Zheng et al., 2018)

Keberadaan CO telah diprakirakan telah menyebabkan 4,9 juta kematian pada tahun 2017 (Stanaway et al., 2018). Paparan CO akan sangat berbahaya jika terhirup oleh manusia karena gas ini dapat mengakibatkan gagal jantung kongestif, penyakit jantung, dan penyakit kardiovaskular (Europe, 2010)

Keberadaan $\mathrm{CO}$ akan akan menggantikan posisi oksigen yang berkaitan dengan hemoglobin dalam darah. Karbon monoksida adalah gas yang bersifat membunuh makhluk hidup termasuk manusia. Pada kasus darah yang tercemar karbon monoksida dalam kadar 70\% hingga $80 \%$ dapat menyebabkan kematian. Karbon Monoksida (CO) adalah gas yang tidak berbau, tidak berasa dan tidak berwarna. Gas CO dapat berbentuk cairan pada suhu -
1290C. Karbon monoksida ini biasanya dihasilkan dari pembakaran tidak sempurna gas bermotor. The World Health Organization (WHO) memperakirakan bahwa kematian akibat polusi udara ambien mengakibatkan 3,7 juta kematian premature diseluruh dunia pada tahun 2012 dan 14 persen diantaranya meninggal karena infeksi pernafasan bawah (Organization, 2014)

Dewasa ini kesadaran akan lingkungan sudah meningkat. Masalah pencemaran yang terjadi di Indonesia sudah banyak menarik perhatian. Pembangunan yang dilakukan besar-besaran di Indonesia dapat meningkatkan kemakmuran bagi masyarakat namun disisi lain hal ini juga dapat membawa dampak negatif terhadap lingkungan hidup masyarakat tersebut. Dampak yang diakibatkan dari pencemaran lingkungan yang di sinyalir dari buangan proses industri dari perusahaan manufaktur yang mengakibatkan rusaknya ekosistem serta mengakibatkan sejumlah penyakit di masyarakat sekitar.

Lokasi pemantauan berada pada jalan Jalan Barukang III yang terletak di Kelurahan Pattingaloang Kecamatan Ujung Tanah Kota Makassar yang merupakan salah satu wilayah di Kota Makassar dengan tata guna lahan meliputi, pemukiman warga, warung/pedagang kaki lima, dan fasilitas umum lainnya.

Fungsi dominan pada Jalan Barukang 
III adalah jalur alternatif bagi masyarakat perkantoran, pendidikan dan perdagangan. Pola penggunaan lahan pada tersebut mengalami perkembangan sesuai tuntutan peningkatan pertumbuhan ekonomi dan perkembangan jumlah penduduknya. hal itu dapat dilihat pada lahan-lahan yang ada di sekitar Jalan Barukang III, area perdagangan tumbuh dan meningkat, pedagang kaki lima dan tidak adanya tempat parkir yang memadai untuk memenuhi kebutuhan akttivitas masyarakat memicu kurang nyamannya keberadaan masyarakat di Jalan Barukang III.

Masalah transportasi di Jalan Barukang III merupakan masalah yang sama seperti yang dihadapi oleh negara-negara yang telah maju (developed) dan juga oleh negara-negara yang sedang berkembang (developing) di bidang transportasi perkotaan (urban) maupun transportasi antar kota (regional). Terciptanya suatu sistem transportasi atau perhubungan yang menjamin pergerakan manusia dan/atau barang secara lancar, aman, cepat, murah dan nyaman merupakan tujuan pembangunan di sektor perhubungan (transportasi).

Penelitian serupa pernah dilakukan Hasil pengukuran di tiga titik menunujkkan bahwa Kadar karbon monoksida (CO) di terminal Karombasan Manado, tidak melebihi baku mutu udara ambien yaitu
$30.000 \mu \mathrm{g} / \mathrm{Nm} 3$ yang mengacu pada Peraturan Pemerintah No. 41 Tahun 1999 tentang baku mutu udara ambien nasional (Tahendung et al., 2018). Selain itu penelitian lain yang dilaksanakan oleh (Devita Nur et al., 2017) memperoleh bahwa rata-rata karbon monoksida dalam udara di gerbang tol Semarang berada di bawah baku mutu, namun terdapat 9 titik pengukuran yang memiliki nilai konstrasi CO yang melebihi nilai ambang batas.

Penelitian lain yang dilakukan (Wahyuni et al., 2019) dengan rancanagan jenis penelitian kuantitatif dengan metode Analisis Risiko Kesehatan Lingkungan (ARKL).Dengan jumlah populasi 222 responden dan sampelnya sebanyak 143 responden. Hasil penelitian menunjukkan rata-rata konsentrasi $\mathrm{CO}$ dalam udara ambien di Sekitar SD Negeri Kakatua tahun 2017 yaitu 968,11 $\mu \mathrm{g} / \mathrm{Nm} 3$. Nilai laju asupan udara anak sekolah di SD Negeri Kakatua yaitu paling tinggi 3,0 m3/hari dan paling rendah 2,4 m3/hari. Nilai durasi paparan anak sekolah di SD Negeri Kakatua yaitu paling tinggi 6 tahun dan paling rendah 4 tahun. Rata-rata besaran risiko (RQ) CO pada anak sekolah di SD Negeri Kakatua yaitu $\mathrm{RQ}<1$. Nilai $\mathrm{RQ}<1$ yang artinya anak sekolah di SD Negeri Kakatua belum terjadi risiko paparan Karbon Monoksida yang terkandung di udara ambient, mes- kipun paparan $\mathrm{CO}$ anak sekolah 
masih belum terjadi risiko tetapi perlu mendapatkan perhatian

Tujuan dari pelaksanaan kegiatan ini adalah untuk membandingkan kualitas udara parameter $\mathrm{CO}$ (karbon monoksida) sebelum dan seletah program CSR Dinding Asri PT Pertamina MOR VII Integrated Terminal (IT) Makassar dengan melakukan analisis dampak kualitas udara parameter CO (karbon monoksida) sebelum dan seletah program CSR Dinding Asri PT Pertamina MOR VII Integrated Terminal (IT) Makassar berdasarkan Indeks Pencemaran Standar Pencemar Udara (ISPU) di sekitar Kelurahan Pattingaloang, Kecamatan Ujung Tanah, Kota Makassar sehingga hasil dari kegiatan ini dapat menjadi suatu gambaran data dan informasi kualitas udara parameter CO (karbon monoksida) sebagai dasar untuk membuat kebijakan dan upaya pengendalian pencemaran udara di Kota Makassar.

\section{METODE PENELITIAN}

Konsentrasi Karbon monoksida (CO) diperoleh dengan melakukan pengukuran udara ambien di 3 (tiga) titik lokasi sampling menggunakan alat CO Meter Lutron GCO-2008 yang dilakukan oleh laboran Laboratorium Kesehatan Masyarakat FKIK UIN Alauddin Makassar. Pengambilan sampel dlakukan dengan metode monitoring dengan desain studi komparatif. Metode monitoring disini artinya pengukuran kon- sentrasi CO dilakukan dalam sepanjang hari dengan tiga sesi pengukuran yaitu pagi, siang dan sore hari dan kemudian menganalisis pebandingan kualitas udara parameter CO sebelum dan setelah Program CSR Dinding Asri PT Pertamina MOR VII Integrated Terminal (IT) Makassar.

Pengambilan sampel dilakukan dengan meggunakan alat $\mathrm{CO}$ Meter Lutron GCO2008 (Digital). Cara pengambilan sampel udara CO ini sesuai SNI 19-7119.10-2011 dan di uji di Laboratorium Kesehatan Masyarakat FKIK UIN Alauddin Makasar.

Pemantauan kualitas udara ambien dengan parameter $\mathrm{CO}$ dilaksanakan dua tahap yakni: (1) sebelum dan saat program CSR dilaksanakan, yakni pada Tanggal 30 Nopember 2019 selama satu hari dengan 3 kali pengukuran, yakni pagi (pukul $07.00-$ 08.00), siang (pukul $12.00-13.00$ ), dan sore (pukul 17.00 - 18.00), sedangkan tahap (2) Setelah program CSR dilaksanakan, yakni pada Tanggal 7 Februari 2020 selama satu hari dengan 3 kali pengukuran, yakni pagi (pukul 07.00 - 08.00), siang (pukul 12.00 - 13.00), dan sore (pukul $17.00-$ 18.00).

Lokasi intervensi program CSR Dinding Asri PT Pertamina MOR VII Integrated Terminal (IT) Makassar yaitu di sepanjang jalan Barukang III, Pattingaloang, Ujung Tanah, Makassar. Area ini termasuk dengan konsentrasi pencemar tinggi, kepadatan 
penduduk tinggi serta berada sekitar lokasi sumber pencemar primer.

Pengambilan sampel dilakukan pada 3 (tiga) titik. Pada prinsipnya penentuan titik sampling berdasarkan data yang diperoleh harus dapat mewakili daerah yang berpotensi tercemar gas karbon monoksida (CO) yaitu titik (1) di Ujung Timur Jalan Barukang III, Pattingaloang, Ujung Tanah,
Lingkungan Hidup Nomor KEP 45/MENLH/1997 yaitu dengan menghitung nilai konsentrasi pencemar udara dalam satuan ppm yang kemudian akan dikonversi ke dalam ISPU (tanpa satuan). Output dari pengolahan data ini bertujuan untuk memberikan kemudahan dari keseragaman informasi kualitas udara ambien kepada masyarakat di lokasi dan waktu tertentu

Tabel 1. Hasil Pengukuran Karbon Monoksida

\begin{tabular}{ccccccccc}
\hline \multirow{2}{*}{ Parameter } & \multirow{2}{*}{ Tanggal Pengukuran } & Ti- & \multicolumn{3}{c}{ Waktu Pengukuran } & Rata- & \multirow{2}{*}{ NAB } & Satuan \\
\cline { 4 - 6 } & Tahap I & I & 25,34 & 22,21 & 26,02 & 24,52 & \\
& & II & 24,22 & 15,78 & 22,65 & 20,88 & \\
\multirow{2}{*}{ CO } & (30 Nopember 2019) & III & 19,21 & 23,97 & 25,60 & 22,93 & 30,00 & PPM \\
& Tahap II & I & 18,23 & 10,74 & 22,34 & 17,10 & \\
& & II & 15,19 & 6,77 & 16,97 & 12,98 & \\
\hline
\end{tabular}

Sumber: Data Primer, 2020

Makassar (persimpangan Jalan Barukang III dan Jalan Barukang Raya) dengan titik koordinat (S.05006.845' E.119025.377'). Titik (2) di pertengahan Jalan Barukang III, Pattingaloang, Ujung Tanah, Makassar dengan titik koordinat (S.05006.861' E.119025.326'). dan titik (3) di Ujung Barat Jalan Barukang III, Pattingaloang, Ujung Tanah, Makassar (Batas lokasi intervensi) dengan titik koordinat (S.05006.895' E.119025.223').

Teknik pengolahan data menggunakan perhitungan analisis Indeks Standar Pencemar Udara (ISPU) yang mengacu pada Keputusan Menteri Negara serta sebagai bahan pertimbangan dalam melakukan upaya-upaya pengendali pencemaran udara.

Dengan dilakukannya perhitungan ISPU, dapat ditentukan parameter yang menunjukkan nilai ISPU yang tertinggi atau terendah sehingga dapat menentukan kriteria dan penjelasan pengaruh dari nilai ISPU. Setelah itu diberikan ulasan singkat mengenai upaya penanganan dalam memperbaiki kualitas udara menjadi stabil, sehingga keseimbangan ekosistem tetap terjaga yang didasarkan pada Keputusan Menteri Negara Lingkungan Hidup No. 45 Tahun 1997. 


\section{HASIL PENELITIAN}

Hasil pemantauan dan pengukuran yang telah dilakukan secara 2 tahap. Tahap Pertama yaitu sebelum/saat program dilaksanakan pada tanggal 30 Nopember 2019, sedangkan Tahap Kedua yaitu setelah program dilaksanakan pada tanggal 7 Februari 2020 di Jalan Barukang III Kota Makassar. Hasil yang di dapatkan di lapangan disajikan dalam bentuk table dan narasi sebagai berikut : konsentrasi $\mathrm{CO}$ tertinggi juga terjadi pada waktu sore hari berada di titik I yaitu sebesar 22,34 ppm, sedangkan untuk konsentrasi CO paling rendah terjadi pada waktu siang hari berada di titik III yaitu 6,60 ppm.

Berdasarkan gambar 1 diatas diketahui pula bahwa nilai rata-rata tertinggi konsentrasi CO pada pengukuran tahap I (pertama) terdapat pada titik I yaitu sebesar 24,52 ppm dan terendah terdapat pada titik II yaitu sebesar 20,88 ppm, sedangkan nilai rata-rata

Tabel 2. Hasil Analisis Indeks Standar Pencemaran Udara

\begin{tabular}{|c|c|c|c|c|c|c|c|c|}
\hline \multirow{2}{*}{ Parameter } & \multirow{2}{*}{$\begin{array}{l}\text { Tanggal Pen- } \\
\text { gukuran }\end{array}$} & \multicolumn{3}{|c|}{ Lokasi (ppm) } & \multirow{2}{*}{$\begin{array}{l}\text { Rata- } \\
\text { Rata } \\
(\mathrm{ppm})\end{array}$} & \multirow{2}{*}{$\begin{array}{c}\text { Nilai } \\
\text { ISPU } \\
(\mathrm{SI}) \\
\end{array}$} & \multirow{2}{*}{ Rentang } & \multirow{2}{*}{ Kategori } \\
\hline & & I & II & III & & & & \\
\hline \multirow{2}{*}{$\mathrm{CO}$} & Tahap I & 24,52 & 20,88 & 22,93 & 22,78 & 203 & $200-299$ & $\begin{array}{c}\text { Sangat Tidak } \\
\text { Sehat }\end{array}$ \\
\hline & Tahap II & 17,10 & 12,98 & 13,57 & 14,55 & 169 & $101-199$ & Tidak Sehat \\
\hline
\end{tabular}

Sumber: Data Primer, 2020

Berdasarkan hasil pengukuran kadar Karbon Monoksida (CO) di lapangan, konsentrasi CO yang didapatkan dalam satuan ppm. Hasil pengukuran konsentarsi CO dapat dilihat pada tabel 1 yang menunjukkan bahwa pada pengukuran tahap I (pertama) di 3 (tiga) titik lokasi sampling, konsentrasi $\mathrm{CO}$ tertinggi terjadi pada waktu sore hari berada di titik I yaitu sebesar 26,02 ppm, sedangkan untuk konsentrasi CO paling rendah terjadi pada waktu siang hari berada di titik II yaitu sebesar 15,78 ppm. Selanjutnya, pada pengukuran tahap II (kedua) tertinggi konsentrasi $\mathrm{CO}$ pada tahap II (kedua) terdapat pada titik I yaitu sebesar 17,10 ppm dan konsentrasi CO terendah pada II yaitu sebesar 12,98 ppm.

Berdasarkan hasil analisis diatas, maka diketahui bahwa konsentrasi CO tertinggi terjadi pada tahap I (pertama) dalam hal ini sebelum/saat dilaksanakannya program CSR Dinding Asri PT Pertamina MOR VII Integrated Terminal (IT) Makassar di lokasi titik I pengambilan sampel dengan nilai rata-rata perhari yaitu sebesar 24,52 ppm. Bila dibandingkan dengan standard baku mutu 
ambien udara, tidak terdapat satupun titik yang melebihi nilai ambang batas $(30,00$ ppm).

Dari hasil pengukuran kadar karbon monoksida (CO) dilapangan, konsentrasi CO yang didapatkan dalam satuan ppm kemudian di analisis dengan menggunakan analisis Indeks Standar Pencemaran Udara (ISPU) dalam satuan SI

Pada tabel 2 menunjukkan bahwa hasil Analisis Indeks Standar Pencemaran Udara (ISPU) parameter $\mathrm{CO}$ di jalan $\mathrm{Ba}-$ rukang III Kota Makassar yang diperoleh dapat dijelaskan bahwa konsentrasi CO pada Pengukuran Tahap I (pertama) dengan nilai ISPU 203 termasuk kategori Berbahaya, sedangkan pada Tahap II (kedua) dengan nilai ISPU 169 termasuk kategori Tidak Sehat. Berdasarkan analisis tersebut dapat disimpulkan bahwa konsentrasi $\mathrm{CO}$ pada Tahap I (sebelum pelaksanaan program) lebih berisiko dibandingkan dengan Tahap II (setelah pelaksanaan program).

\section{PEMBAHASAN}

Berdasarkan hasil pengukuran diketahui bahwa pada Pengukuran Tahap I (pertama) di memiliki konsentrasi CO tertinggi terjadi pada waktu sore hari berada di titik I yaitu sebesar 26,02 ppm, sedangkan untuk konsentrasi CO paling rendah terjadi pada waktu siang hari berada di titik II yaitu sebesar 13,78 ppm. Selanjut- nya, pada Pengukuran Tahap II (kedua) konsentrasi $\mathrm{CO}$ mengalami penurunan dengan konsentrasi $\mathrm{CO}$ tertinggi terjadi pada waktu sore hari berada di titik I yaitu sebesar 22,34 ppm, sedangkan untuk konsentrasi CO paling rendah terjadi pada waktu siang hari berada di titik II yaitu 6,77 ppm. Hal ini dipengaruhi oleh kondisi lalu lintas yang padat dititik tersebut. Kemacetan jalan umumnya terjadi dititik ini disebabkan oleh ruas jalan yang sempit dan terletak dipersimpangan jalan. Kondisi ini diperkirakan menghasilkan emisi gas $\mathrm{CO}$ yang menyebabkan konsentrasi tinggi diudara. Konsentrasi CO di udara perwaktu dalam satu hari dipengaruhi oleh kesibukan atau aktifitas kendaraan bermotor. Semakin ramai kendaraan motor yang ada maka semakin tinggi tingkat konsentrasi $\mathrm{CO}$ yang ada.

Karbon monoksida adalah senyawa yang sangat beracun namun tidak berwarna dan hampir tidak berbau, sehingga sangat membahayakan kehidupan. Oleh karena itu harus dipantau secara terus menerus. Keberadaannya di udara sebagai akibat dari pembakaran tidak sempurna dari bahan organic seperti kayu, batu-bara, kertas, minyak, dll. Hasil pembakaran kendaraan bermotor yang memakai bahan bakar bensin di udara ambient mengandung CO berkisar 1 $-10 \%$ tergantung dari operasi mesin.

Hasil monitoring kadar $\mathrm{CO}$ di jalan 
Barukang III menunjukkan bahwa konsentrasi $\mathrm{CO}$, baik itu sebelum program maupun sesudah program masih memenuhi syarat (di bawah Nilai baku Mutu sesuai Peraturan Pemerintah No. 41 tentang Pengendalian Pencemar Udara).

Menurut peraturan menteri Tenaga Kerja dan Transmigrasi nomor PER.13/MEN/X/2011 tentang Nilai Am-
Berdasarkan hasil analisis data diatas, maka maka dapat ditarik kesimpulan bahwa dari semua titik pengambilan sampel, konsentrasi CO tertinggi terjadi pada saat/sebelum dilaksanakannya program CSR Dinding Asri PT Pertamina MOR VII Integrated Terminal (IT) Makassar, dibandingkan setelah pelaksanaan program CSR Dinding Asri PT Pertamina MOR VII

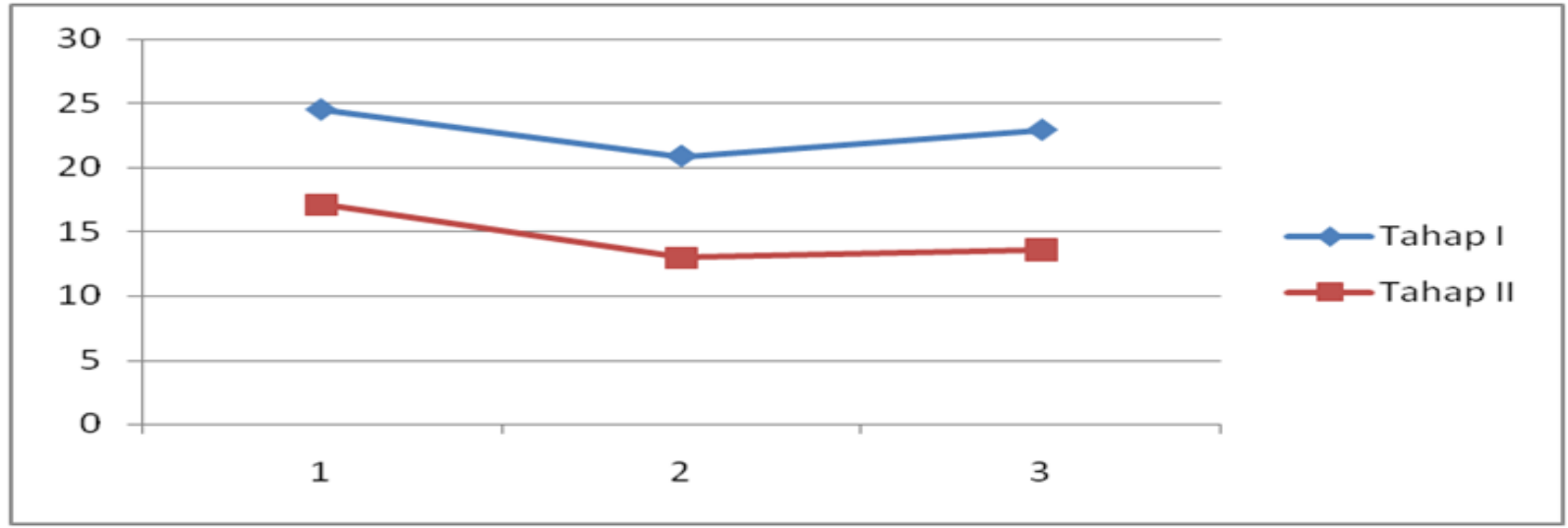

Gambar 1. Grafik Nilai Rata-rata Hasil Pengukuran Karbon Monoksida (CO)

bang Batas (NAB) faktor fisika dan kimia, $\mathrm{CO}$ memiliki NAB sebesar $30.00 \mu \mathrm{g} / \mathrm{Nm} 3$. CO masuk kedalam tubuh manusia melalui proses inhalasi. CO lebih mudah mengikat hemoglobin daripada O2. Hal tersebut menyebabkan terhambatnya pengikatan hemoglobin dengan oksigen.

Mengingat bahaya Karbon monoksida terhadap kesehatan begitu besar maka keberadaan karbon monoksida di udara perlu diwaspadai apalagi bila dikaitkan dengan pertambahan kendaraan bermotor tiap tahunnya yang terus meningkat terutama di daerah perkotaan.
Integrated Terminal (IT) Makassar yang mengalami penurunan konsentrasi pada tiga titik pengambilan sampel.

Bila dibandingkan berdasarkan nilai rata-rata perhari, konsentrasi $\mathrm{CO}$ sebelum pelaksanaan program lebih tinggi dengan nilai rata-rata yaitu sebesar $22,78 \mathrm{ppm}$, sedangkan nilai rata-rata setelah pelaksanaan program berkurang menjadi 14,55 ppm. Adanya perbedaan rata-rata gas $\mathrm{CO}$ pada setiap titik dipengaruhi oleh volume dan laju kendaraan. Kendaraan akan melambat atau berhenti pada titik persimpangan jalan mengakibatkan emisi dari kendaraan di titik 
tersebut lebih banyak dibandingkan dengan jalan tanpa persimpangan, dimana kendaraan akan melaju lancar.

Hal ini membuktikan bahwa upaya yang dilakukan PT Pertamina MOR VII Integrated Terminal (IT) Makassar melalui program CSR sangat efektif dalam meminimalisir dampak pencemaran gas karbon monoksida (CO) di Jalan Barukang III, Kelurahan Pattingaloang, Kecamatan Ujung Tanah, Kota Makassar. Hal ini dipengaruhi oleh salah satu program CSR Dinding Asri PT Pertamina yakni pengadaan dinding asri, yang dimana hampir semua di sepanjang dinding Jalan Barukang III dihiasi oleh tanaman-tanaman hias yang dapat mereduksi kadar dari gas karbon monoksida $(\mathrm{CO})$, selain itu ditunjang juga dengan program-program lainnya seperti pembenahan lorong, kampung safety, serta pembuatan tanaman hydroponik.

PT Pertamina MOR VII Integrated Terminal (IT) Makassar melalui program CSR ini telah mebuktikan kepeduliannya terhadap pengelolaan lingkungan hidup dan memberi kontribusi terhadap perbaikan kualitas udara khususnya dalam mengurangi gas pencemar udara yakni gas karbon monoksida (CO) di Kota Makassar.

Hal ini sejalan dengan penelitian yang dilakukan oleh (Nowak et al., 2018) bahwa keberadaaan pohon kota dapat membantu meningkatkan kualitas udara di kota dan akibatnya dapat membantu meningkatkan kesehatan manusia. Selain meningkatkan kualitas udara, keberadaan pepohonan diperkotaan akan mereduksi polusi udara sebanyak 1 persen. Perubahan kecil ini dapat memengaruhi derajat kesehatan masyarakat di seluruh kota.

Indeks standar pencemaran udara (ISPU) adalah indeks kualitas udara yang digunakan sebagai bahan informasi bagi masyarakat tentang kualitas udara ambien di lokasi dan waktu tertentu. Kualitas udara pada umumnya dinilai dari konsentrasi parameter pencemaran udara yang terukur lebih tinggi atau lebih rendah dari nilai baku mutu ambien nasional.

Hasil analisis ISPU parameter $\mathrm{CO}$ dijalan Barukang III Kota Makassar yang diperoleh pada saat/sebelum dilaksanakannya program (Tahap I) didapatkan nilai ISPU sebesar 203 dan termasuk kategori Sangat Tidak Sehat, sedangkan nilai ISPU setelah dilaksanakannya program didapatkan nilai sebesar 169 yang termasuk kategori Tidak Sehat.

Hal ini menunjukkan bahwa telah terjadi penurunan nilai ISPU setelah terlaksananya program CSR Dinding Asri PT Pertamina MOR VII Integrated Terminal (IT) Makassar yang secara otomatis juga mengurangi resiko bahaya akibat keterpaparan gas $\mathrm{CO}$.

Berdasarkan pengaruh konsentrasi gas 
karbon monoksida terhadap makhluk hidup. Nilai ISPU pada kisaran 200-299 berkategori sangat tidak sehat, paparan gas $\mathrm{CO}$ akan meningkatkan kardiovaskular pada orang bukan perokok yang berpenyakit jantung, dan akan tampak beberapa kelemahan yang terlihat secara nyata. Pada nilai ISPU kisaran 101 - 199, atau masuk kategori Tidak Sehat paparan gas CO dampaknya yaitu peningkatan pada kardiovaskular pada perokok yang sakit jantung.

Gas karbon monoksida merupakan gas yang memiliki dampak kesehatan membahayakan bagi masyarakat berisiko yang berada di sekitar jalan tersebut. Karbon monoksida akan masuk dan berikatan dengan darah membentuk karboksihemoglobin $(\mathrm{COHb})$, dan dapat mengurangi jumlah oksigen yang dibawah oleh hemoglobin di seluruh tubuh (tidak efektif untuk mentransfer oksigen ke jaringan tubuh) kondisi ini dinamakan anoxemia. Gas CO mampu berikatan dengan hemoglobin 210 kali lebih besar dari pada oksigen.

Hal ini sejalan dengan penelitian yang dilakukan oleh (Dengo et al., 2018) yang memaparkan bahwa paparan karbon monoksida terhadap responden tukang parkir, akan mengakibatkan saturasi oksigen kedalam tubuh menjadi tidak normal, dan paparan $\mathrm{CO}$ dalam jumlah yang tinggi juga dapat mengakibatkan keleleahan kerja.

\section{KESIMPULAN}

Nilai Analisis Indeks Standar Pencemar Udara (ISPU) pada saat/sebelum dilaksanakannya program program CSR Dinding Asri lebih beresiko berbahaya terhadap kesehatan yakni sebesar 203 dan masuk dalam kategori sangat tidak sehat, sedangkan nilai ISPU setelah dilaksanakannya Program Dinding Asri mengalami penurunan nilai yakni sebesar 169 dan masuk kategori tidak sehat.

Kualitas udara di Jalan Barukang III Makassar (Lokasi Intervensi Program CSR Dinding Asri), mengalami perbaikan kualitas udara setelah dilaksanakannya Program CSR Dinding Asri PT Pertamina MOR VII Integrated Terminal (IT) Makassar.

\section{SARAN}

Program CSR oleh pihak perusahaan/industri yang mengutamakan aspek pengelolaan lingkungan hidup yang bersifat sustainability seperti penghijauan atau penanaman pohon perindang di sekitar kawasan sumber emisi (industri dan jalan raya). Mempertahankan dan mengembangkan ruang terbuka hijau serta taman kota. Kami berharap kepada Pemerintah Kota (Pemkot) Makassar agar memperhatikan dan melakukan sistem pemantauan emisi pada kendaraan umum yang banyak beroperasi di jalan raya, selain itu perlunya inisiasi pro- 
gram penanaman pohon akan mengurangi polutan-polutan dari emisi gas buang khususnya karbon monoksida

\section{DAFTAR PUSTAKA}

Dengo, M. R., Suwondo, A., \& Suroto. (2018). Hubungan Paparan CO terhadap Saturasi Oksigen dan Kelelahan Kerja pada Petugas Pakir The Correlation between $\mathrm{CO}$ Exposure on Oxygen Saturation and the Work Fatigue of the Parking Attendants. Gorontalo: Journal of Public Health, 1, 78-84. http://www.jurnal.unigo.ac.id/index.p $\mathrm{hp} / \mathrm{gjph} /$ article/view/347

Derrible, S., Saneinejad, S., Sugar, L., \& Kennedy, C. (2010). Macroscopic Model of Greenhouse Gas Emissions for Municipalities. Transportation Research Record: Journal of the Transportation Research Board, 2191(1), 174-181.

https://doi.org/10.3141/2191-22

Devita Nur, A., Nurzazuli, \& Tri, J. (2017). Analisis Risiko Kesehatan Lingkungan Pajanan Gas Karbon Monoksida (Co) Pada Petugas Pengumpul Tol Di Semarang. Jurnal Kesehatan Masyarakat, 5(3), 367-375.

Europe, W. H. O. R. O. for. (2010). WHO guidelines for indoor air quality: selected pollutants. World Health Organization. Regional Office for $\mathrm{Eu}-$ rope.

https://apps.who.int/iris/handle/10665/ 260127

Ismiyati, Marlita, D., \& SAidah, D. (2014). Pencemaran Udara Akibat Emisi Gas Buang Kendaraan Bermotor. 01(03), 241-248.

Nowak, D. J., Hirabayashi, S., Doyle, M., McGovern, M., \& Pasher, J. (2018).
Air pollution removal by urban forests in Canada and its effect on air quality and human health. Urban Forestry and Urban Greening, 29(October 2017), 40-48.

https://doi.org/10.1016/j.ufug.2017.10 .019

Organization, W. H. (2014). Ambient (outdoor) air quality and health. Fact Sheet, 313.

Stanaway, J. D., Afshin, A., Gakidou, E., Lim, S. S., Abate, D., Abate, K. H., Abbafati, C., Abbasi, N., Abbastabar, H., Abd-Allah, F., Abdela, J., Abdelalim, A., Abdollahpour, I., Abdulkader, R. S., Abebe, M., Abebe, Z., Abera, S. F., Abil, O. Z., Abraha, H. N., ... Murray, C. J. L. (2018). Global, regional, and national comparative risk assessment of 84 behavioural, environmental and occupational, and metabolic risks or clusters of risks for 195 countries and territories, 19902017: a systematic analysis for the Global Burden of Disease Stu. The Lancet, 392(10159), 1923-1994. https://doi.org/10.1016/S01406736(18)32225-6

Tahendung, A. A., Rokot, A., \& Kabuhung, A. (2018). Kadar Karbon Monoksida ( Co ) Di Terminal Karombasan. Jurnal Kesehatan Lingkungan, 8(1), 23-26.

Wahyuni, S., Susilawaty, A., Bujawati, E., \& Basri, S. (2019). Analisis Risiko Paparan Karbon Monoksida (Co) Terhadap Anak Sekolah Di Sd Negeri Kaka Tua Kota Makassar Tahun 2017. Higiene, $5(1)$, 43. https://doi.org/10.1017/CBO97811074 15324.004

Wardhana, W. A. (1995). Dampak pencemaran lingkungan. Andi Offset. https://books.google.co.id/books?id=b EHbAAAAMAAJ 
Zheng, B., Chevallier, F., Ciais, P., Yin, Y., Deeter, M. N., Worden, H. M., Wang, Y., Zhang, Q., \& He, K. (2018). Rapid decline in carbon monoxide emissions and export from East Asia between years 2005 and 2016. Environmental Research Letters, 13(4), 044007. https://doi.org/10.1088/1748-

9326/aab2b3 